\section{CONJUNTO RESIDENCIAL DE RIDDARSPORREN}

$123-144$
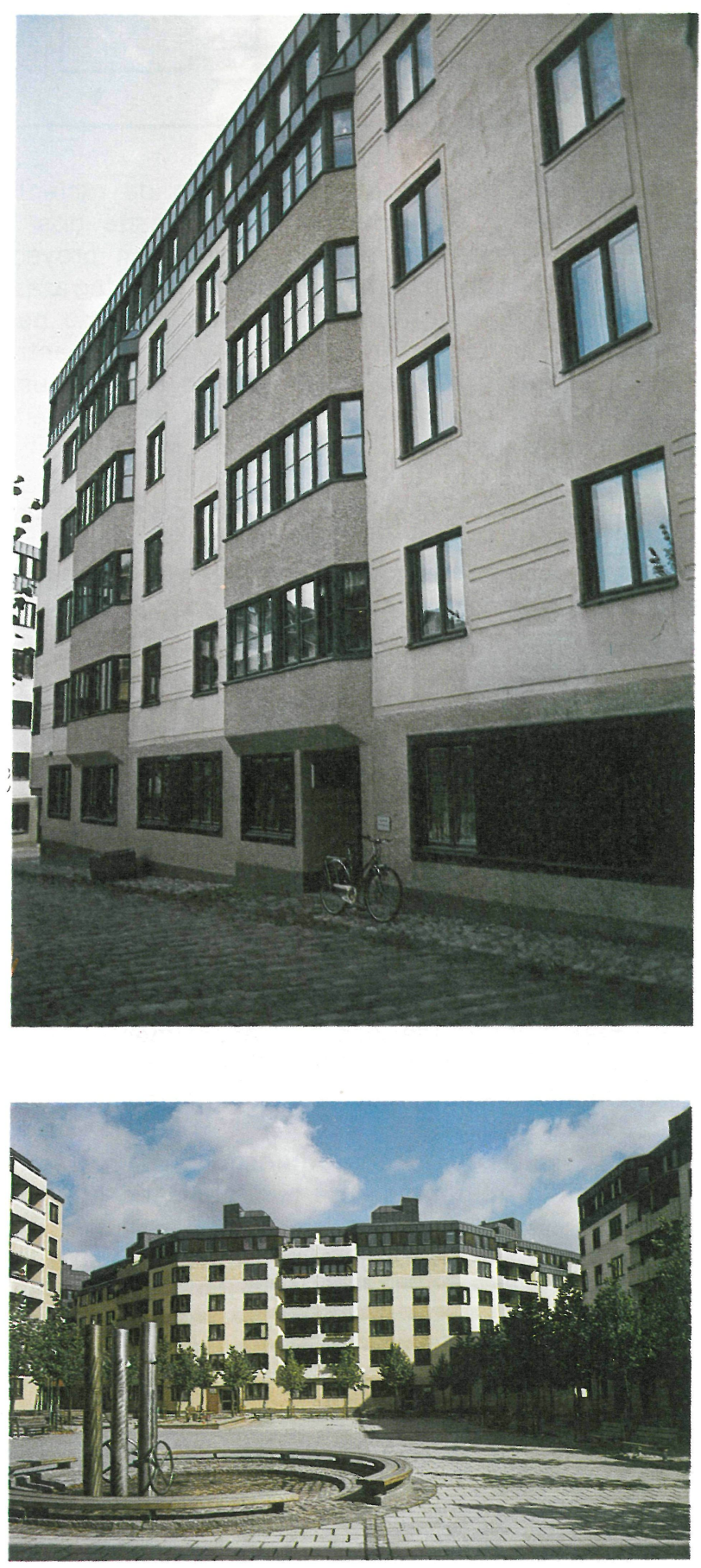

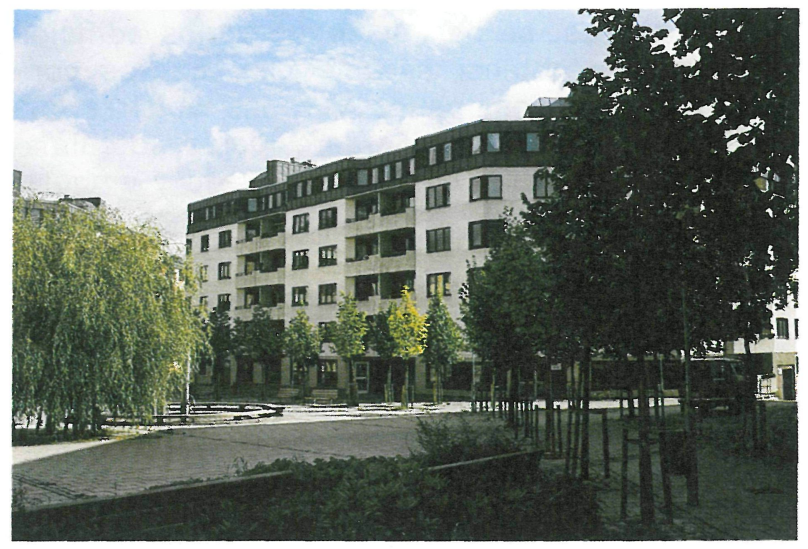

La cervecería de Hamburgo:

antecedentes históricos resumidos

La cervecería de Hamburgo ha formado parte de este conjunto desde 1875, cuando Franz Heiss, uno de los propietarios, adquirió dos grandes parcelas en dicha zona, en las que se emplazó la primera edificación de la cervecería: un sótano de almacenaje. No fue hasta nueve años después cuando las parcelas se utilizaron para más edificaciones, surgiendo así, en pocos años, una cervecería amplia y moderna. Al mismo tiempo, se construvó la casa del director gerente con su fachada hacia Norrtullsgatan.

Posteriormente, la compañia adquirió más parcelas de este emplazamiento y las utilizó para construir un pequeño conjunto residencial y un edificio de tiendas. Un recinto de fermentación en dos plantas se construyó bajo el patio. En 1888 se acabó la cervecería y se pudo iniciar la producción. En 1889, la Hamburg Brewery se fusionó en la Stockholm Breweries Inc., que compró parcelas adicionales para su expansión en 1903.

Un gran número de mujeres se contrataron para el lavado, llenado, encorchado y etiquetado de las botellas. La mayoría de ellas procedía de la provincia sueca de Dalecarlia, en donde las mujeres eran famosas por su fuerza y resistencia como trabajadoras. Uno de los edificios del conjunto (todavía en pie) se construyó especialmente como dormitorio para estas trabajadoras y se le dio el nombre de "Casa Dalecarliana".

Después de 1910, una serie de ampliaciones y de modernizaciones se sucedieron de forma rápida. En 1964, Stockholm Breweries se fusionó con Pripp Breweries, continuando la producción bajo el nombre de. Pripp hasta que dejó de hacerlo en 1970. En 1974, el ayuntamiento de Estocolmo adquirió el terreno, con el fin primordial de conse- 
guir acceso a los emplazamientos centralmente situados, para la construcción de conjuntos residenciales.

Desde entonces, se han demolido varios edificios antiguos para obtener espacio para nuevos conjuntos residenciales, patios y zonas abiertas. Se han derribado la instalación de calderas, los almacenes, los talleres, el edificio de lavado y embotellado, el establo, la herrería, el cobertizo de carruajes y las viviendas. Por el contrario la cervecería, la casa del director gerente, la "Casa Dalecarliana", el silo y las viviendas en Hagagatan y Surbrunnsgatan están siendo objeto de completa renovación y reconstrucción. La antigua sala de fermentación se convertirá en un garaje.

El ejemplo de este conjunto sirve para demostrar que la renovación urbana puede realizarse con cuidado y consideración, que es posible conservar los viejos edificios de valor cultural e histórico y restaurar y modernizar en combinación con la construcción de nuevos edificios que puedan mezclarse armoniosamente y de forma natural con el entorno antiguo.

Los dibujos representan los edificios antiguos en su estado original y la combinación actual de edificios conservados y de conjuntos residenciales de reciente construcción.

\section{Los edificios antiguos}

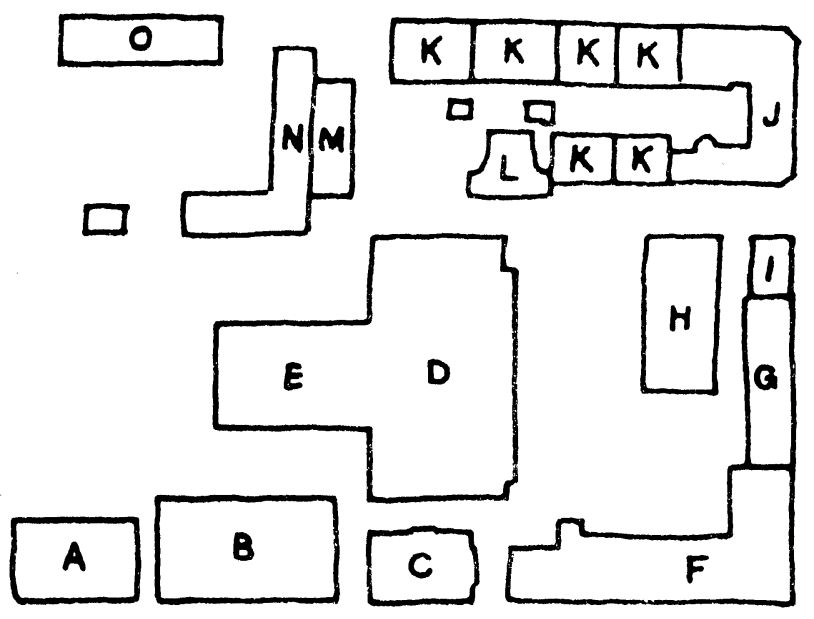

A. La cervecería.

B. La instalación de calderas.

C. La casa del director gerente, viviendas y oficinas.

D. Almacenes, talleres, recinto de fermentación.

E. Edificio de lavado y de embotellado.

F. Silo y almacén.

G. Edificio de oficinas $y$ residencial.
H. Establo, recintos del forraje y cobertizos. alojamientos para las mujeres trabajadoras.

J. Viviendas de propiedad privada.

K. Viviendas.

L. Talleres.

M. Garaje.

N. Establo, herrería.

O. Recinto de carruajes.
1. La "Casa Dalecarliana",

\section{La zona nueva}
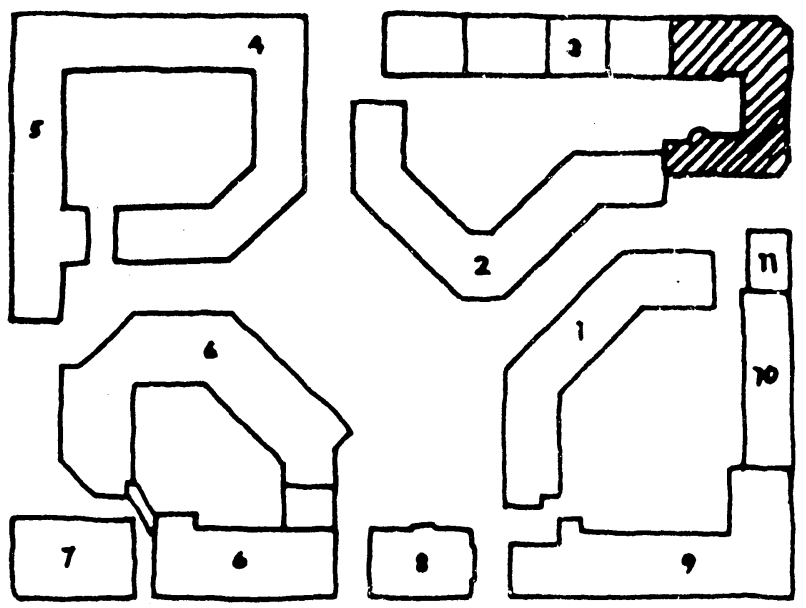

Los edificios núms. 1, 2, 4 y 5 son de reciente construcción y contienen viviendas desde dos a cinco habitaciones. Varias viviendas están proyectadas como apartamentos duplex o con terrazas. Dos guarderías con tres unidades cada una se han emplazado en los edificios $n .^{\circ} 1$ y 5 . Un centro recreativo está ubicado en el edificio $n .^{\circ} 2$ y una de las dos lavanderías del conjunto está situada en el mismo edificio.

El edificio n. ${ }^{\circ} 3$ está constituido realmente por varias de las viviendas antiguas de Hagagatan y Surbrunnsgatan. Algunos de los edificios son propiedad actualmente del Ayuntamiento de Estocolmo, mientras que otros son propiedad de las asociaciones de arrendatarios-propietarios. Todas las viviendas están completamente renovadas, con nuevos ascensores y una nueva distribución de apartamentos. Las fachadas se restauraron de forma que recuperaran su estado original. La zona sombreada en el anterior diagrama adjunta al edificio $n .^{\circ} 3$ es una casa de viviendas de propiedad privada y no forma parte del proyecto de construcción.

El edificio $n .^{\circ} 6$ es una residencia para pensionistas. Está constituida por 174 apartamentos más un despacho de asistencia social, sala de actividades, centro médico, peluquería, quiropodista, la-

vandería, sala de juegos, quiosco y restaurante. La entrada al restaurante da hacia el patio interior.

El edificio $n .^{\circ} 7$ era originalmente la cervecería de la fábrica y está declarado monumento histórico. Este edificio está provisto de una conexión con la residencia de los pensionistas y se utiliza para reuniones, etc. Se ha construido un gran auditorio en el vestíbulo de la cervecería, con una entrada en Norrtullsgatan especialmente concebida para personas físicamente disminuidas. Las dos plantas por encima de la zona de entrada de la cervecería contienen salas de reunión y clubs, más peque- 
ños. También se ha previsto espacio para exposiciones. El sótano se utiliza para salas de ejercicios físicos.

El edificio n. ${ }^{\circ} 8$ es la casa del director gerente de la antigua cervecería. Algunas secciones de la casa, declarada monumento histórico, están bien conservadas. Se están realizando estudios actualmente para determinar una actividad adecuada para el espléndido interior de este edificio. La fachada de la casa que mira hacia el nuevo patio interior se considera algo desproporcionada y se modificará ligeramente para darle un mejor aspecto desde esa dirección.

El edificio $n .^{\circ} \boldsymbol{9}$ era el silo y lugar de almacenaje para la cervecería. La profundidad del edificio del silo y sus zonas abiertas a nivel del suelo le convirtieron en un emplazamiento adecuado para la delegación local de la seguridad social. En las si- guientes dos plantas situadas encima, hay un centro de asistencia social. Por encima de este último se han distribuido 45 apartamentos, de los cuales 25 son parte de la residencia de pensionistas. En el sótano que mira hacia el patio interior, se ubica una lavandería y una sala de juntas para los arrendatarios. Gracias al diseño del antiguo edificio del silo, las actividades pueden desarrollarse también por la noche en los recintos del sótano, sin riesgo de que los demás inquilinos sean molestados por el ruido.

El edificio $n .^{\circ} 10$ es una casa de viviendas que se mantiene en su estado originario después de realizadas las reparaciones oportunas.

El edificio n..$^{11}$, la "Casa Dalecarliana", es una construcción de viviendas que se transformó para proporcionar instalaciones al personal administrativo, junto con tres apartamentos.

\section{publicación del i.e.t.c.c.}

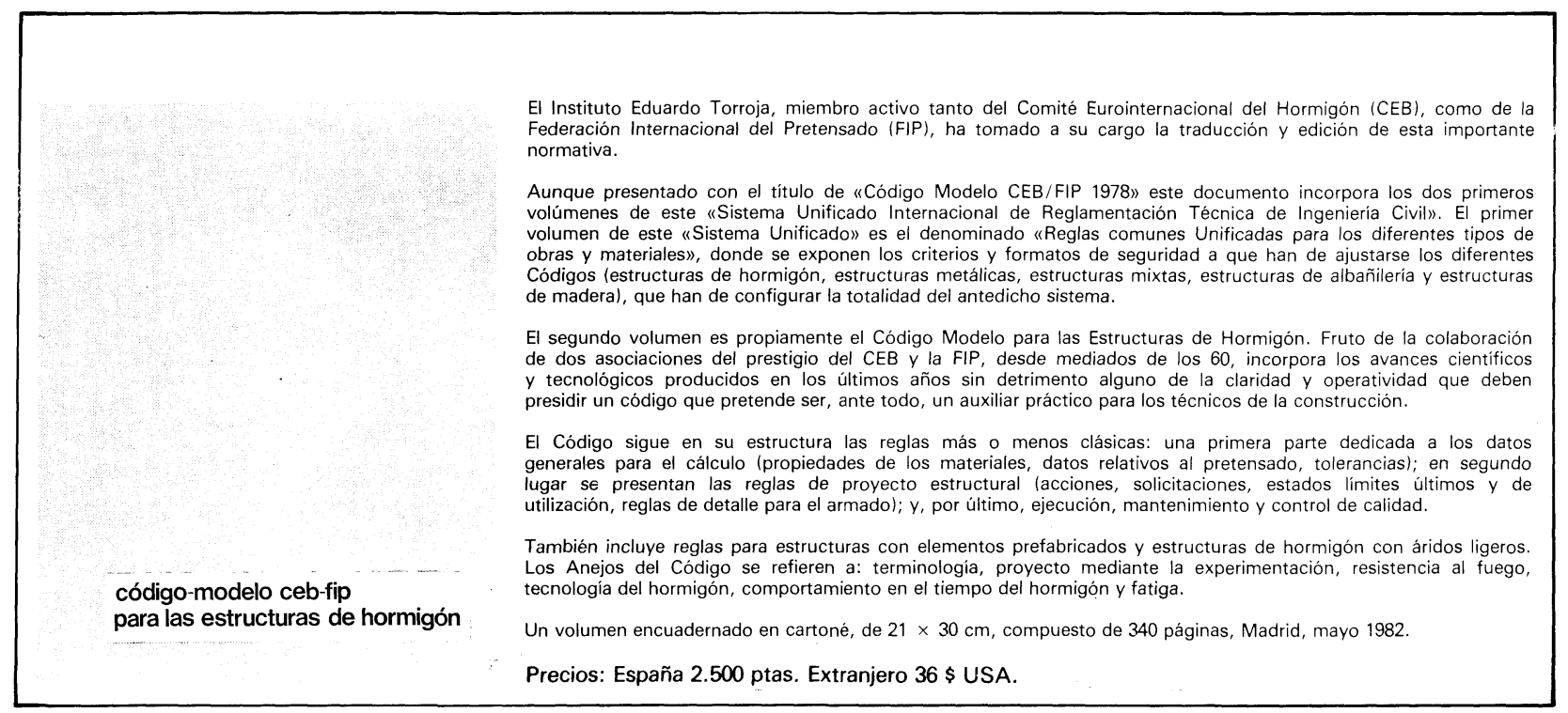

